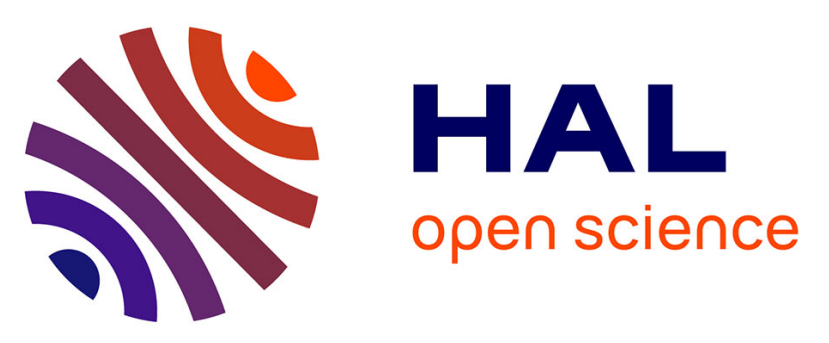

\title{
Real-Space Approach to the Reaction Force: \\ Understanding the Origin of Synchronicity/Nonsynchronicity in Multibond Chemical Reactions
}

Diana Yepes, Julen Munárriz, Julia Contreras-García, Pablo Jaque

\section{To cite this version:}

Diana Yepes, Julen Munárriz, Julia Contreras-García, Pablo Jaque. Real-Space Approach to the Reaction Force: Understanding the Origin of Synchronicity/Nonsynchronicity in Multibond Chemical Reactions. Journal of Physical Chemistry A, 2020, 124 (10), pp.1959-1972. 10.1021/acs.jpca.9b10508 . hal-02874034

\section{HAL Id: hal-02874034 \\ https: / hal.sorbonne-universite.fr/hal-02874034}

Submitted on 18 Jun 2020

HAL is a multi-disciplinary open access archive for the deposit and dissemination of scientific research documents, whether they are published or not. The documents may come from teaching and research institutions in France or abroad, or from public or private research centers.
L'archive ouverte pluridisciplinaire HAL, est destinée au dépôt et à la diffusion de documents scientifiques de niveau recherche, publiés ou non, émanant des établissements d'enseignement et de recherche français ou étrangers, des laboratoires publics ou privés. 
Revised Manuscript prepared for The Journal of Physical Chemistry A, Special Issue: Paul Geerlings Festschrift

\title{
Real space approach to the reaction force: understanding the origin of synchronicity/nonsynchronicity in multi-bond chemical reactions
}

\author{
Diana Yepes, ${ }^{\dagger, \mathbb{I}}$ Julen Munarriz, ${ }^{\S,+, \mathbb{I}}$ Julia Contreras-Garcia, ${ }^{, \S}$ and Pablo Jaque*,\| \\ ${ }^{\dagger}$ Departamento de Ciencias Químicas, Facultad de Ciencias Exactas, Universidad Andres Bello, \\ Av. República 275, Santiago, Chile. \\ ${ }^{\S}$ Sorbonne Université, CNRS, Laboratoire de Chimie Théorique, CC 137 - 4, place Jussieu, F- \\ 75252 Paris Cedex 05, France \\ " Departamento de Química Orgánica y Fisicoquímica, Facultad de Ciencias Químicas y \\ Farmacéuticas, Universidad de Chile, Olivos 1007, Santiago, Chile. \\ * E-mail : Julia.Contreras@1ct.jussieu.fr; pablo.jaque@ ciq.uchile.cl
}

\section{ORCID}

DY: 0000-0003-4211-7162

JM : 0000-0001-6089-6126

JCG: 0000-0002-8947-9526

PJ : 0000-0002-4055-3553

T Contributed equally to this work.

‡ Currently at the Department of Chemistry \& Biochemistry, University of California, Los Angeles (UCLA), Los Angeles, California 90095, United States. 


\begin{abstract}
In this article, we present a complementary analysis based on the reaction force $\mathbf{F}(\xi) /$ reaction force constant $\kappa(\xi)$ and non-covalent interactions (NCI) index to characterize the energetics (kinetic and thermodynamics) and mechanistic pathways of two sets of multi-bond chemical reactions, namely, two double proton transfer and two Diels-Alder cycloaddition reactions. This approach offers a very straightforward and useful way to dwell into the deeper understanding of this type of processes. While $\mathbf{F}(\xi)$ allows the partition of the whole pathway into three regions or phases, $\kappa(\xi)$ describes how orchestrated are the bond breaking and formation events. In turn, NCI indicates how the inter- and intra-molecular bonds evolve. The most innovative aspect is the inclusion of the formation of the reactant complex along the pathway, which, by means of NCI, unveils the early molecular recognition and the comprehension of its role in determining the degree of the synchronicity/nonsynchronicity of one-step processes. This approach should be a useful and alternative tool to characterize the energetics and the mechanism of general chemical reactions.
\end{abstract}




\section{Introduction}

Multi-bond chemical reactions are those in which two or more covalent bonds are formed and/or broken. They can proceed either in a single kinetic step without an intermediate or in a stepwise mechanism where a diradical or zwitterionic species is suggested as intermediate. ${ }^{1}$ In the former case the bond breaking and/or formation can occur in unison, i.e. synchronously, or through a highly asynchronous mode, currently defined as two-stage one-step mechanism, thus a time gap between the bond forming processes appears. ${ }^{1-3}$ Note that a complete gradation in asynchronicities lies between these two extremes, i.e. fully synchronous to fully asynchronous processes, or even when the latter converts into a stepwise mechanism, which can be seen as an extreme case of asynchronicity. ${ }^{2-7}$ The most widely used criterion to characterize this mechanistic concept, for instance in Diels-Alder reactions, has been the (a)symmetry of the emerging C-C bond distances at the transition state. ${ }^{8-10}$ However, this approach provides a continuum scale of (a)synchronicities making it hard to rank the different flavors between synchronous to two-stage one-step mechanisms, or even the transition into a stepwise mechanism. In this context, the features of the fine structure of the reaction force constant, $\kappa(\xi),{ }^{11}$ along the transition regions defined within the reaction force frame, ${ }^{12}$ have been proved to be directly related to the formation of the new bonds. Consequently, it has been used to reliably reveal the synchronicity level as well as to show how it is affected by the presence of catalysts ${ }^{13}$ or the solvent polarity in prototypical multi-bond chemical reactions, such as double proton transfer reactions ${ }^{14,15}$ and Diels-Alder cycloadditions. ${ }^{4-6,16-18}$

The progress of single-step multi-bond chemical reactions can be characterized by following the motion along the minimum-energy pathway (also known as the intrinsic reaction coordinate (IRC) $\xi$, expressed in mass-weighted Cartesian coordinates ${ }^{19,20}$ ) connecting the transition state (TS) to the reactants $(\mathbf{R})$ and products $(\mathbf{P})$. Generally, the reaction profiles are 
referred to the isolated reactants (see Figure 1a). However, different works have drawn attention to the key role the reactant complexes (RC) (also known as van der Waals or pre-organized complexes) could be playing in a specific reaction pathway. ${ }^{21}$ This species corresponds to a minimum on the potential energy surface (as shown Figure 1b) and gives rise to the earliest molecular recognition between the reactants involving both the reactive centers (which will form the new covalent bonds) and any other fragments that could be assisting the initial assembling. Concomitantly, the non-covalent interactions at the $\mathbf{R C}$, are mostly responsible of its stability and can even be strengthened along $\xi$ until the proximities of the transition state. In this last region the covalent interactions become dominant, thus driving the process towards the final products. ${ }^{22-}$ ${ }^{24}$ In this sense, the scope of these interactions in determining the initial orientation mode of the reactants can be responsible of the mechanistic issues that have been exclusively ascribed to the TS such as the stereo- and regioselectivity, as well as the synchronicity/asynchronicity of multibond chemical reactions. ${ }^{17,25}$

(a)

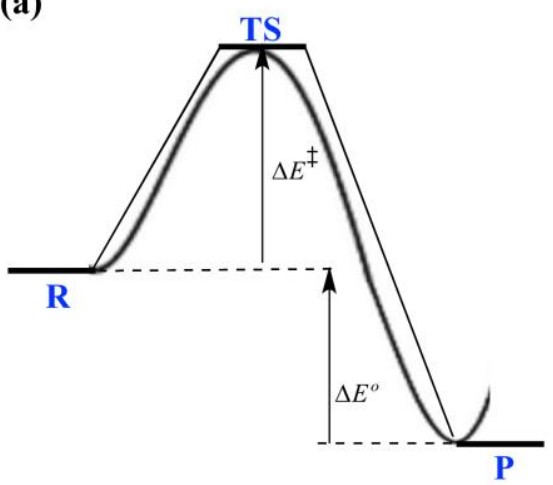

(b)

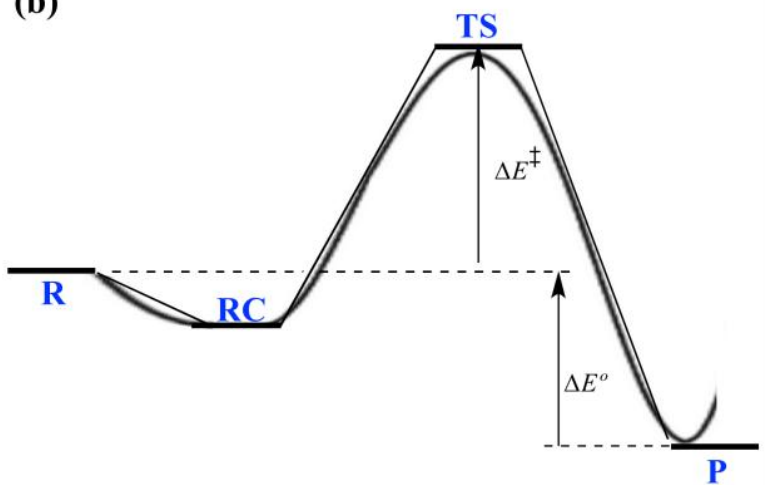

Figure 1. Prototypical potential energy profiles (a) without and (b) with reactant complex (RC).

Therefore, a deeper understanding of the reaction mechanisms can be achieved by combining the classical IRC-based analyses with the specific role of non-covalent interactions (the so-called molecular recognition). The synergy between both approaches constitutes a 
valuable tool to provide important information into the origin of the regio- and/or stereochemical selectivity, paving the way towards the rational design of novel chemical systems (such as catalysts) with improved performance. ${ }^{25,26}$

Other different approaches have been developed for such purposes, in this sense; the bonding evolution theory (BET) also constitutes a powerful tool to rationalize the electron reorganization along the molecular mechanism for a variety of chemical processes. ${ }^{27-31}$

In the current work, we present a study of two double proton transfer reactions and two $[4+2]$-cycloadditions. They take place in a single kinetic step, but within each set, one reaction is fully synchronous and the other one has a highly asynchronous mechanism (see Scheme 1). The main goal of this contribution is to scrutinize how the non-covalent/covalent interactions evolve along the reaction pathway. Special attention is paid to the key points defined by the reaction force model, in order to determine their role in the (a)synchronicity in both set of reactions, going beyond the TS-symmetry based criterion.

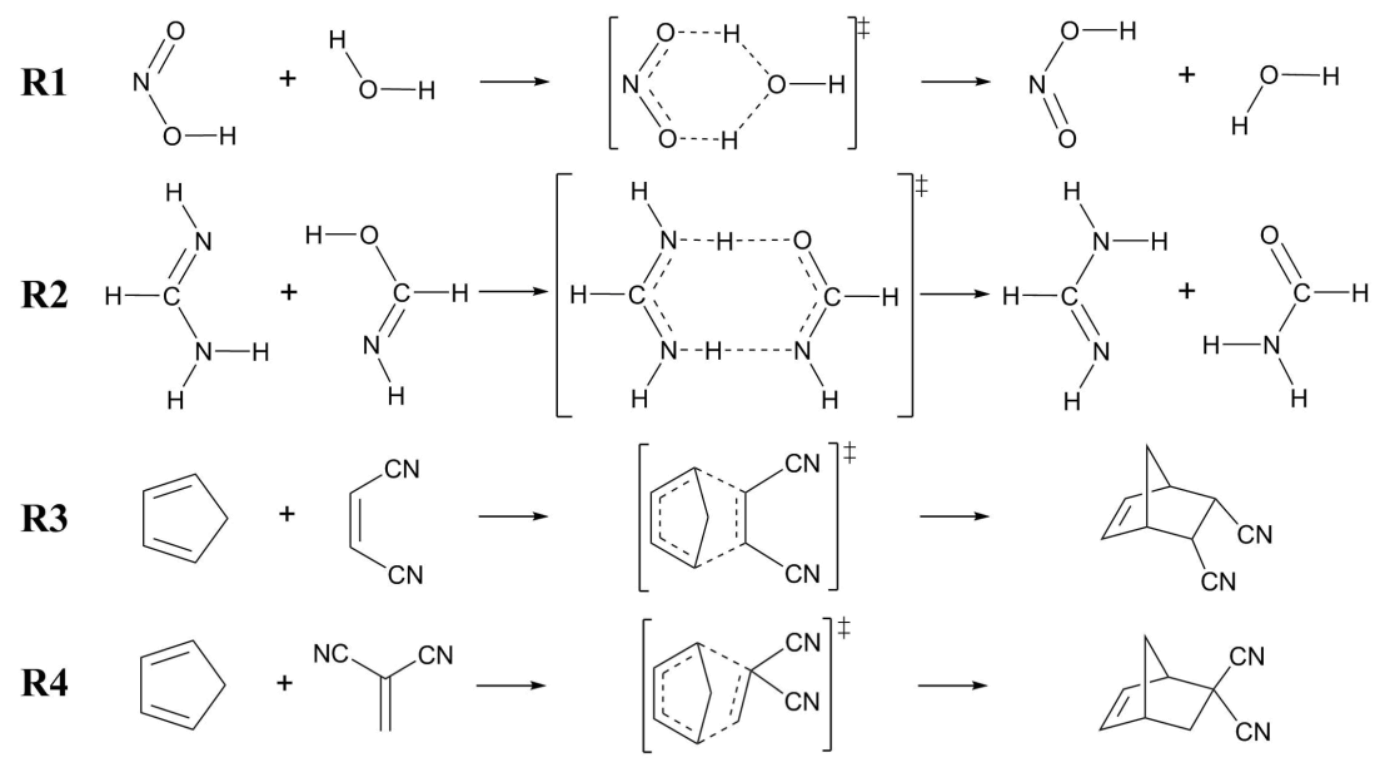

Scheme 1. Double proton transfer reactions and $[4+2]$-cycloadditions considered in this study. 


\section{Theoretical Background}

\section{The Reaction Force and the Reaction Force Constant}

For a conservative physical system, the negative gradient of a potential energy is a force, and the second derivative is a force constant. In analogy, for a chemical process that takes place in a single kinetic step, the reaction force $\mathbf{F}(\xi),{ }^{12}$ and the reaction force constant, $\kappa(\xi),{ }^{11}$ can be respectively defined assimilating $\xi$ to a displacement, as stated in eqs. 1 and 2:

$$
\begin{aligned}
& \mathbf{F}(\boldsymbol{\xi})=-\frac{\partial \mathrm{U}(\boldsymbol{\xi})}{\partial \boldsymbol{\xi}}, \\
& \kappa(\xi)=\frac{\partial^{2} \mathrm{U}(\boldsymbol{\xi})}{\partial \xi^{2}}=-\frac{\partial \mathbf{F}(\boldsymbol{\xi})}{\partial \xi} .
\end{aligned}
$$

Figure 2a-f illustrates the corresponding generic profiles of $\mathrm{U}(\boldsymbol{\xi}), \mathbf{F}(\boldsymbol{\xi})$ and $\kappa(\xi)$ for a fully synchronous (left-panels) and a highly asynchronous two-stage (right-panels) reaction, respectively. For both processes the potential energy $U(\xi)$ is quite similar in the proximities of the maximum, $\xi_{\mathrm{TS}}$ (which corresponds to the TS). On the contrary, the derivatives of $\mathrm{U}(\xi)$ exhibit remarkable differences, which have been directly related with the (a)synchronicity degree of the mechanism..$^{5-7,15-18,32,33}$

$\mathbf{F}(\xi)$ and $\xi$ are vectors pointing from reactants $(\mathbf{R})$ to products $(\mathbf{P})$. The reaction force profiles $\mathbf{F}(\boldsymbol{\xi})$ (Figures $2 \mathrm{c}$ and $2 \mathrm{~d}$ ) are the result of the forces acting over the system at any point along $\xi$. Notice that $\mathbf{F}(\xi)$ is negative along the activation process (i.e. from $\mathbf{R}$ to $\mathbf{T S}$ ) indicating that it is retarding in nature, therefore, energy is required. On the contrary, it is positive along the relaxation process (i.e. from $\mathbf{T S}$ to $\mathbf{P}$ ) indicating that it is supporting the motion along $\xi$, consequently, energy is released. It can be also noted that $\mathbf{F}(\boldsymbol{\xi})$ presents two critical points, a 
minimum at $\xi_{1}$ and a maximum at $\xi_{2}$. They split the process into three segments labeled as reactant (from $\xi_{\mathrm{R}}$ to $\xi_{1}$ ), transition (from $\xi_{1}$ to $\xi_{2}$ ), and product regions (from $\xi_{2}$ to $\xi_{\mathrm{P}}$ ). Different studies have unveiled that in the middle stage most of the electronic events (such as bond breaking/forming and charges redistribution) are accentuated while the geometrical changes (bond lengthening, rotations, etc.) are mainly emphasized during both sided regions. ${ }^{34-41}$

With respect to the reaction force constant profiles (Figures $2 \mathrm{e}$ and $2 \mathrm{f}$ ), $\kappa(\xi)$ is positive in the structurally-intensive first and third regions, whereas $\kappa(\xi)$ is negative along the electronicallyintensive regions, i.e. transition regions. Therefore, we can establish a clear picture for both $U(\xi)$ profiles studied thus far: $\kappa(\xi)$ is negative within the transition region and for the fully synchronous mechanism (left-panels) there is only one $\kappa(\xi)$ minimum $\left(\kappa(\xi)_{\min 1}\right)$ (Figure 2e). On the contrary, for the highly asynchronous one (right-panels) two minima $\left(\kappa(\xi)_{\min 1}\right.$ and $\left.\kappa(\xi)_{\min 2}\right)$ connected by one negative maximum $\left(\kappa(\xi)_{\max }\right)$ are revealed (Figure 2f). Previous studies have revealed that for moderate asynchronous processes $\kappa(\xi)$ displays a minimum with a shoulder, while for an extremely asynchronous reaction the negative maximum of $\kappa(\xi)$ becomes a positive maximum of $\kappa(\xi)$, which is an indicative that the mechanism changes from a one step to stepwise one. ${ }^{6,7,15}$

The transition region goes beyond the traditional transition state and its existence is experimentally supported by the transition state spectroscopy of Zewail and Polanyi, which defines a continuum of transient, unstable states between perturbed forms of the reactants and products, where all bond breaking and formation processes occur. ${ }^{42,43}$ 

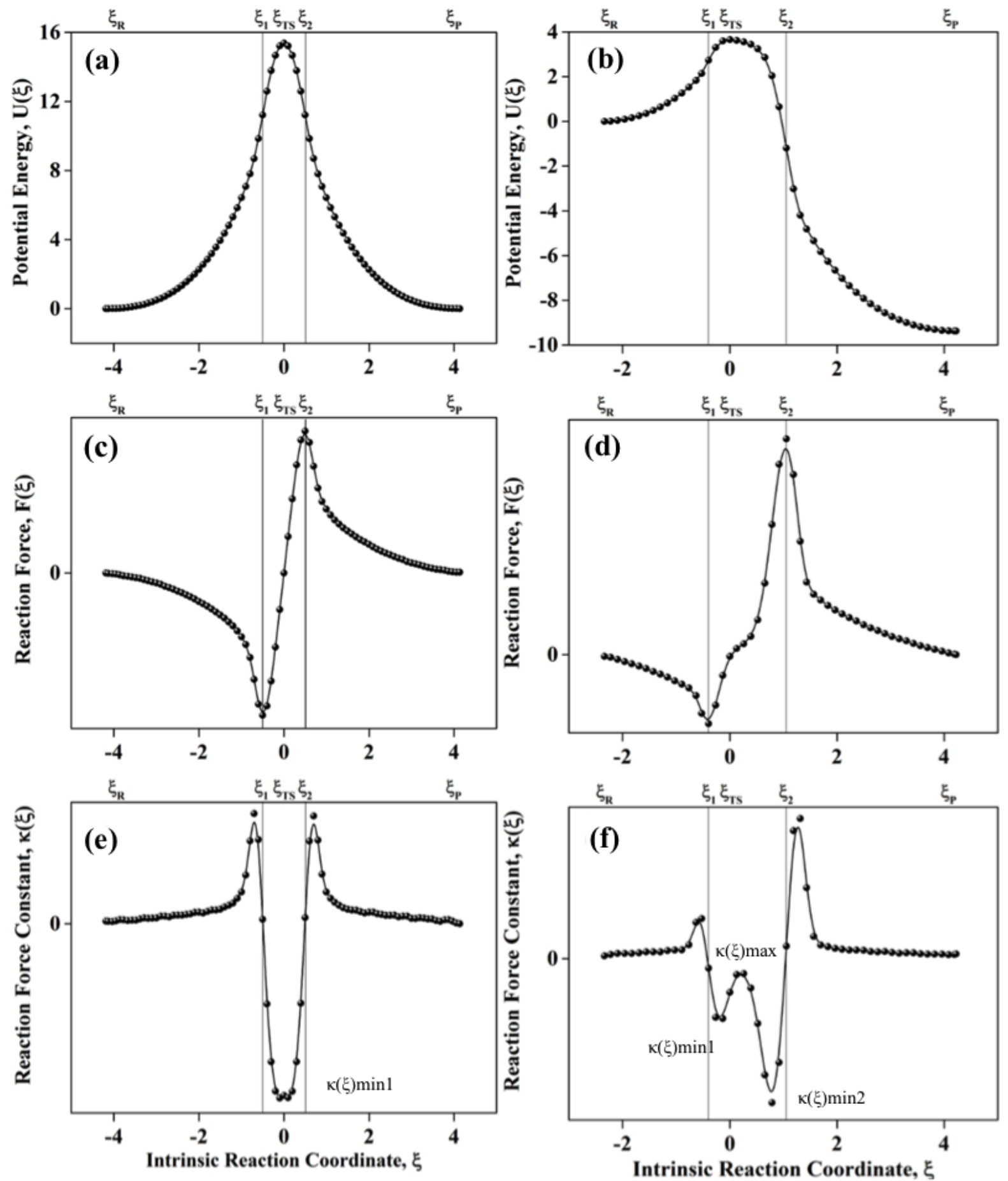

Figure 2. Generic profiles of (a)-(b) $U(\xi),(c)-(d) \mathbf{F}(\xi)$ and (e)-(f) $\kappa(\xi)$ along the intrinsic reaction coordinate $\xi$ for a synchronous (left-panels) and an asynchronous (right-panels) one-step mechanism. 


\section{Non-Covalent Interactions (NCI) Index}

During any multi-bond chemical reaction, namely double proton transfer and [4+2] cycloaddition reactions, intra and intermolecular bonds are expected to change. In order to follow those changes we have resorted to the NCI index (for Non-Covalent Interactions). NCI is a method for the identification, characterization and visualization of interactions on the basis of the electron density and its derivatives, enabling to identify and classify non-covalent interactions by means of the peaks that emerge in the reduced density gradient at low-density regions. ${ }^{44}$ In particular, the procedure localizes minima of the reduced density gradient $s$ (see eq. 3), which appear as a consequence of the interference between the different atoms that constitute a given system.

$$
s=\frac{1}{2\left(3^{2}\right)^{1 / 3}} \frac{|\nabla|}{4 / 3}
$$

Most commonly, these regions are located around electron density critical points (although there are some exceptions). ${ }^{45}$ This enables the reconstruction of a 3D image of the quantum theory of atoms in molecules $(\mathrm{QTAIM})^{46}$ where the relationship between critical points is recovered visually (i.e. the information commonly conveyed by bifurcation diagrams is retrieved directly by visual inspection of isosurfaces). The approach is able to reveal both attractive and repulsive interactions. ${ }^{44}$ Namely, it has proved to be a useful tool in the study of a broad range of non-covalent interactions, such as hydrogen and halogen bonds, as well as in the design of hybrid materials, among many others. ${ }^{47-49}$

A color code is used to differentiate the type of interaction. Namely, strong attractive interactions, such as hydrogen bonds, are depicted in blue; very weak interactions, such as van 
der Waals, are shown in green, and strong repulsive interactions, like steric clashes, are colored in red. Since these surfaces appear for all bonding types (from strong to weak, from covalent to ionic), ${ }^{50,51}$ they are specially suitable for following reactivity studies in real space and compare them to the insight obtained from energy derivatives (reaction force/reaction force constant).

\section{Computational Details}

All stationary points on the potential energy profiles were fully optimized using the hybrid B3LYP exchange-correlation functional ${ }^{52,53}$ combined with the standard triple- $\zeta$ augmented with d- and p-type polarization functions, 6-311G(d,p,) basis set for double proton transfer reactions. Instead, the range-separated hybrid with semiclassical London-dispersion, the $\omega B$ 97XD functional, ${ }^{54}$ combined with the standard double- $\zeta$ augmented with $d$ - and p-type polarization and diffuse functions, 6-31+G(d,p) basis set was employed for Diels-Alder cycloadditions. These levels of theory were chosen due to their reported good performance in each type of multi-bond reaction. ${ }^{5,15,55}$ The nature of the stationary points in the potential energy surface was confirmed through harmonic vibrational analyses: zero imaginary frequency for energy minima and one for transition states. The associated eigenvectors of TSs were validated to correspond to the motion along the minimum energy path by using the IRC procedure ${ }^{19,20}$ with a step size of $0.10 \mathrm{amu}^{1 / 2}$ bohr. The IRC procedure typically concludes in the RC, therefore, we extrapolate it until to move apart the interacting molecules and thus achieve energy profiles as displayed Figure 1b. These calculations were carried out using the Gaussian09 suite of programs. $^{56}$

NCI plots were computed by means of the NCIPLOT software, ${ }^{57}$ by using the respective monodeterminantal B3LYP/6-311G(d,p) and $\omega \mathrm{B} 97 \mathrm{XD} / 6-31+\mathrm{G}(\mathrm{d}, \mathrm{p})$ wavefunctions for double proton transfer and Diels-Alder reactions, respectively. A cutoff of 1.0 a.u. in the density was 
chosen for the 3D visualization in order to ensure that both intra and intermolecular bonds could be visualized simultaneously. ${ }^{58}$ All $s$ isosurfaces were represented, by taking an isovalue of 0.2 a.u. Since we wanted to study simultaneously both covalent and non-covalent interactions, an unusually large color range $\left(\operatorname{sign}\left(\lambda_{2}\right) \rho\right.$ from -0.5 to 0.5 a.u.) has been used. Electron density values at the bond critical point (BCP) were obtained with the AIMAll package. ${ }^{59}$

\section{Results and Discussion}

The results are divided into two sections, one for each type of multi-bond chemical reaction. Energetics together with the degree of synchronicity will be firstly discussed, while the origin of the (a)synchronicity will be thus understood by scrutinizing how intermolecular interactions along $\xi$ evolve.

\section{Double Proton Transfer: Synchronous vs. Asynchronous Mechanisms.}

The double proton transfer reactions considered in the present study consist on reactions involving hydrogen-bonded complexes (as $\mathbf{R C}$ ) between the weak nitrous acid $\left(\mathrm{HNO}_{2}\right)$ in its cis rotamer and water (R1) and between formamidic acid (FMA) and formamidine (FI) (R2) as displayed Scheme 2, where the labels are included for the following discussion on the density at the BCP.

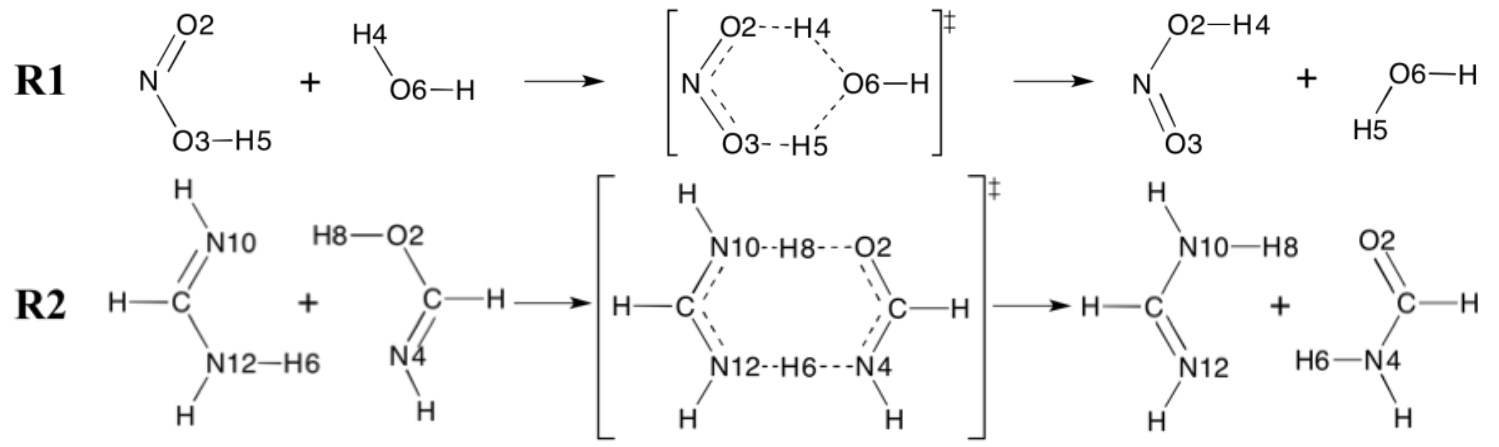

Scheme 2. Double proton transfer reactions between H-bonded complexes. 
Notice that while R1 proceeds via a symmetrical TS, R2 does so via an asymmetrical TS. Figure 3a-f displays the $\mathrm{U}(\boldsymbol{\xi})(\mathrm{a}-\mathrm{b}), \mathbf{F}(\boldsymbol{\xi})(\mathrm{c}-\mathrm{d})$ and $\kappa(\boldsymbol{\xi})(\mathrm{d}-\mathrm{f})$ profiles for R1 (left-panels) and $\mathbf{R} 2$ (right-panels), respectively. In addition to the minimum energy path provided by the IRC calculations, the formation (in reactant side) and breaking (in product side) of $\mathrm{H}$-bonded complexes (i.e. RC) is also included as suggested Figure 1b. Concomitantly, the profile can be divided into three phases: (I) the initial formation of the RC, (II) the double proton exchange reaction and (III) the separation of the products. 

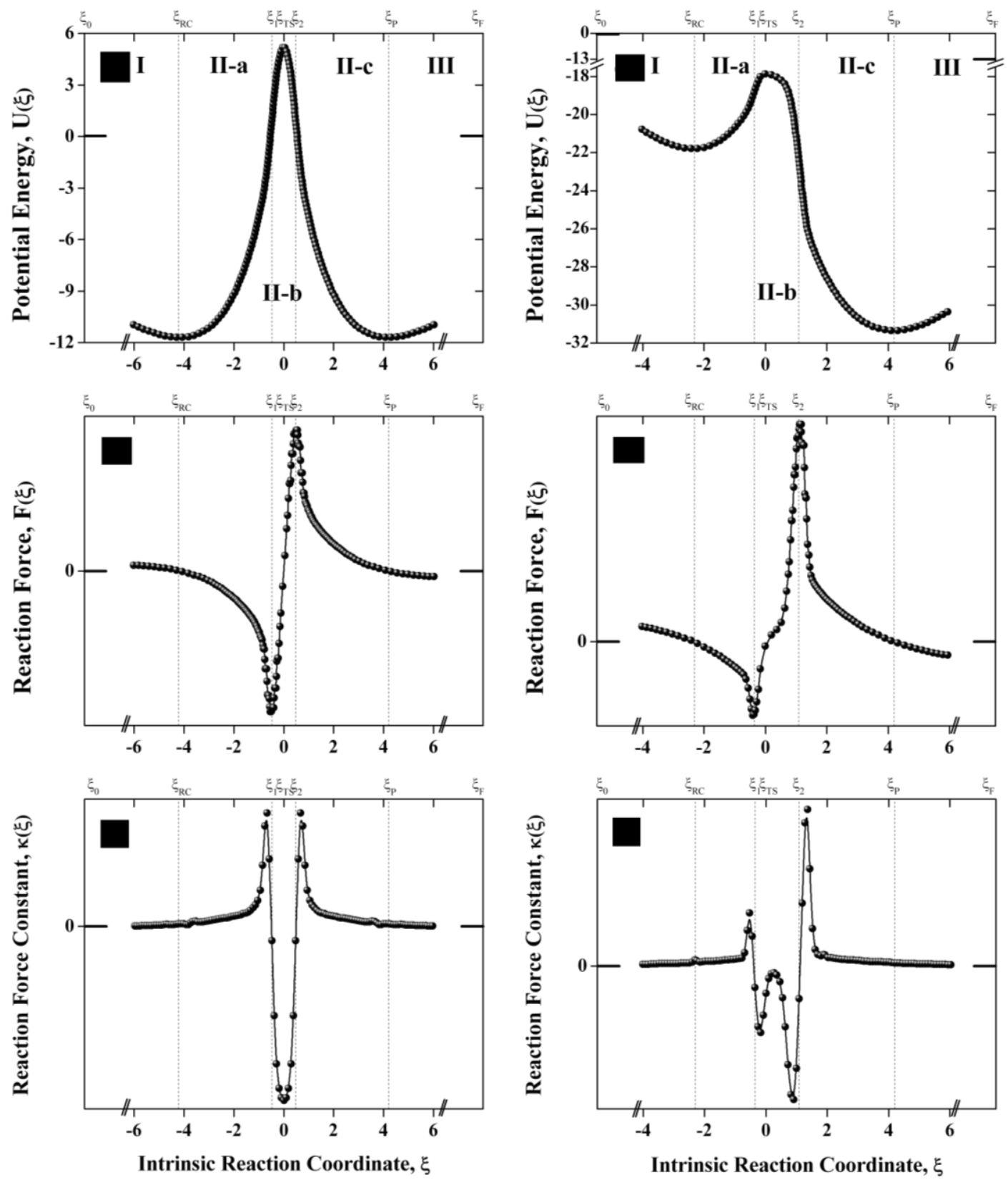

Figure 3. Profiles of $\mathrm{U}(\xi), \mathrm{F}(\xi)$ and $k(\xi)$ along $\xi$ for synchronous R1 (left-panels) and asynchronous $\mathbf{R 2}$ (right-panels) double proton transfer reactions.

The initial changes, part (I) from $\xi_{0}$ to $\xi_{\mathrm{RC}}$, indicate the structural modifications that molecules undergo so as to approach each other through the two H-bonding interactions between the atoms $\mathrm{O}_{2} \cdots \mathrm{H}_{4} / \mathrm{H}_{5} \cdots \mathrm{O}_{6}$ in $\mathbf{R} 1$ and $\mathrm{N}_{10} \cdots \mathrm{H}_{8} / \mathrm{H}_{6} \cdots \mathrm{N}_{4}$ in $\mathbf{R 2}$, thus leading to the formation of the 
H-bonded complexes located at $\xi_{\mathrm{RC}}$. The formation of the H-bonded complex is a barrier-free process in which energy is released, being more stable in $\mathbf{R 2}$ than the corresponding one in $\mathbf{R} \mathbf{1}$ (21.8 vs. $11.7 \mathrm{kcal} \mathrm{mol}^{-1}$ ). That is the formamidic acid (FMA) $\cdots$ formamidine (FI) H-bonded complex is more stable than the $\mathrm{HNO}_{2} \cdots \mathrm{H}_{2} \mathrm{O}$ complex.

After the formation of $\mathbf{R C}$, the double proton exchange reaction takes place and is identified as part (II) in Figure 3, which, in turn, is divided into three regions: II-a, II-b, and II-c. Note that it corresponds to the description of the reaction force analysis given in Figure 2a-f. Therefore, during part II-a (from $\xi_{\mathrm{RC}}$ to $\xi_{1}$ ), the so-called reactant region; structural rearrangements are predominant over the electronic ones. The amount of energy $\left(\mathrm{U}\left(\xi_{1}\right)-\mathrm{U}\left(\xi_{\mathrm{RC}}\right)\right)$ needed to overcome the increasing hindrance to the structural changes in part II-a is higher in $\mathbf{R} \mathbf{1}$ than the analogous in $\mathbf{R} 2$ (11.2 vs. $2.7 \mathrm{kcal} \mathrm{mol}^{-1}$ ). With respect to part II-b (i.e. from $\xi_{1}$ to $\xi_{2}$ ) it corresponds to the transition region, where the electronic reorganizations are enhanced. The involved energy $\left(\mathrm{U}\left(\xi_{2}\right)-\mathrm{U}\left(\xi_{1}\right)\right)$ can be decomposed into two terms: $\left(\mathrm{U}\left(\xi_{\mathrm{TS}}\right)-\mathrm{U}\left(\xi_{1}\right)\right)$ and $\left(\mathrm{U}\left(\xi_{2}\right)\right.$ $\mathrm{U}\left(\xi_{\mathrm{TS}}\right)$ ), which are respectively $5.7 \&-5.7 \mathrm{kcal} \mathrm{mol}^{-1}$ for $\mathbf{R} \mathbf{1}$ and $1.2 \&-5.4 \mathrm{kcal} \mathrm{mol}^{-1}$ for $\mathbf{R 2}$. While the first component is positive in accord with a retarding force, the second one is negative, since a positive force is driving the process. Consequently, energy is required and released, respectively. In agreement with this partition, the activation energy referred to $\mathbf{R C}$ can be written in terms of two contributions, the amount of energy of part II-a and the first component of part IIb, i.e. $\Delta \mathrm{E}_{\mathrm{act}}=\mathrm{U}\left(\xi_{\mathrm{TS}}\right)-\mathrm{U}\left(\xi_{\mathrm{RC}}\right)=\mathrm{U}\left(\xi_{1}\right)-\mathrm{U}\left(\xi_{\mathrm{RC}}\right)+\mathrm{U}\left(\xi_{\mathrm{TS}}\right)-\mathrm{U}\left(\xi_{1}\right)$. The activation energies and contributions are: 16.9 (11.2 \& 5.7) $\mathrm{kcal} \mathrm{mol}^{-1}$ for $\mathbf{R} 1$ and 3.9 (2.7 \& 1.2) $\mathrm{kcal} \mathrm{mol}^{-1}$ for $\mathbf{R 2}$. We thus noted that $\mathbf{R} \mathbf{2}$ is kinetically more favored than $\mathbf{R} \mathbf{1}$ and that the energy barriers are mainly controlled by structural rearrangements. Moreover, the kinetic feasibility of $\mathbf{R} 2$ is also provided 
by a lower energy associated with electronic reorganizations. Both contributions to the energy barrier are determined by the strength of the hydrogen-bonding interactions unveiled in part I.

Finally, part II-c ( $\xi_{2}$ to $\left.\xi_{\mathrm{P}}\right)$ consists on the structural rearrangements that lead toward the formation of the products, the so-called conformational relaxation. The amount of energy released $\left(\mathrm{U}\left(\xi_{\mathrm{P}}\right)-\mathrm{U}\left(\xi_{2}\right)\right)$ are -11.7 and $-8.0 \mathrm{kcal} \mathrm{mol}^{-1}$ for $\mathbf{R} 1$ and $\mathbf{R 2}$, respectively. Notice that the addition of the last four terms defines the thermodynamic driving force. Again, the thermodynamic feasibility of $\mathbf{R} \mathbf{2}$ can also be explained on the stronger H-bonding interactions between FMA and FI that promote the proton exchange to form the new H-bonded complex between formamide (FM) and formamidine (FI).

Finally, part III describes the barrier-free dissociation of the formed H-bonded complex. Because $\mathbf{R} 1$ has a perfectly symmetric profile, the energy needed $\left(\mathrm{U}\left(\xi_{\mathrm{F}}\right)-\mathrm{U}\left(\xi_{\mathrm{P}}\right)\right)$ to move apart the interacting fragments is $11.7 \mathrm{kcal} \mathrm{mol}^{-1}$ while for the FM $\cdots$ FI complex of $\mathbf{R 2} 18.3 \mathrm{kcal} \mathrm{mol}^{-1}$ are required. By comparing the results in parts I and III it is concluded that H-bonded complex between FMA and FI is more stable than that between FM and FI, i.e. $\mathrm{N} \cdots \mathrm{HO} / \mathrm{NH} \cdots \mathrm{N}$ interactions are more stable than $\mathrm{NH} \cdots \mathrm{O} / \mathrm{N} \cdots \mathrm{HN}$ ones. Consequently, the forward reaction is kinetically more favored than the reverse one.

As it can be seen in Figures 3c-d and 3e-f, the $\mathbf{F}(\xi)$ and $\kappa(\xi)$ reveal certain similarity along the structurally-intensive regions, i.e. reactants and products regions. The differences are noted along the electronically-intensive regions, i.e. the transition regions. On one hand, a linear and a non-linear behavior can be noted for $\mathbf{R 1}$ and $\mathbf{R 2}$, respectively. On the other hand, the barrier width, $\xi_{2}-\xi_{1}$, is broader for $\mathbf{R} \mathbf{2}$ than $\mathbf{R} \mathbf{1}$ (see Figure 3c-d, respectively). This suggests that the primitive processes associated with the breaking and formation of $\mathrm{H}$-bonding interactions is 
occurring in a different manner. ${ }^{60}$ The above-mentioned observations are confirmed by the $\kappa(\xi)$ profiles, which are markedly different in the respective transition regions. This fine structure shows a single minimum of $\kappa(\xi)$ within this zone for R1 (see Figure 3e). On the contrary, the shape of $\kappa(\xi)$ along the transition region of $\mathbf{R} 2$ exhibits a local negative maximum connecting to two minima of $\kappa(\xi)$ located sided (see Figure 3f). Therefore, on the basis of these patterns the double proton exchange mechanism can be classified as synchronous for $\mathbf{R} \mathbf{1}$ and asynchronous for $\mathbf{R 2}$, suggesting that the asynchronous character of $\mathbf{R 2}$ could also explain its kinetical feasibility.

By matching the results, we can conclude that a less stable symmetric H-bonded complex is associated with a higher energy barrier where protons are synchronously transferred. Such highly stable asymmetric H-bonded complex is thus related with a lower energy barrier indicating that enhanced bonding interactions promote dynamically delocalized protons and consequently, the protons are asynchronously exchanged.

As previously introduced, the non-covalent interactions were thoroughly studied by means of the NCI index on the key points along $\xi$ defined by the $\mathbf{F}(\xi) / \kappa(\xi)$ analysis (see Table 1). 
Table 1. Plots of the NCI index along the key points for R1 and $\mathbf{R 2}$.

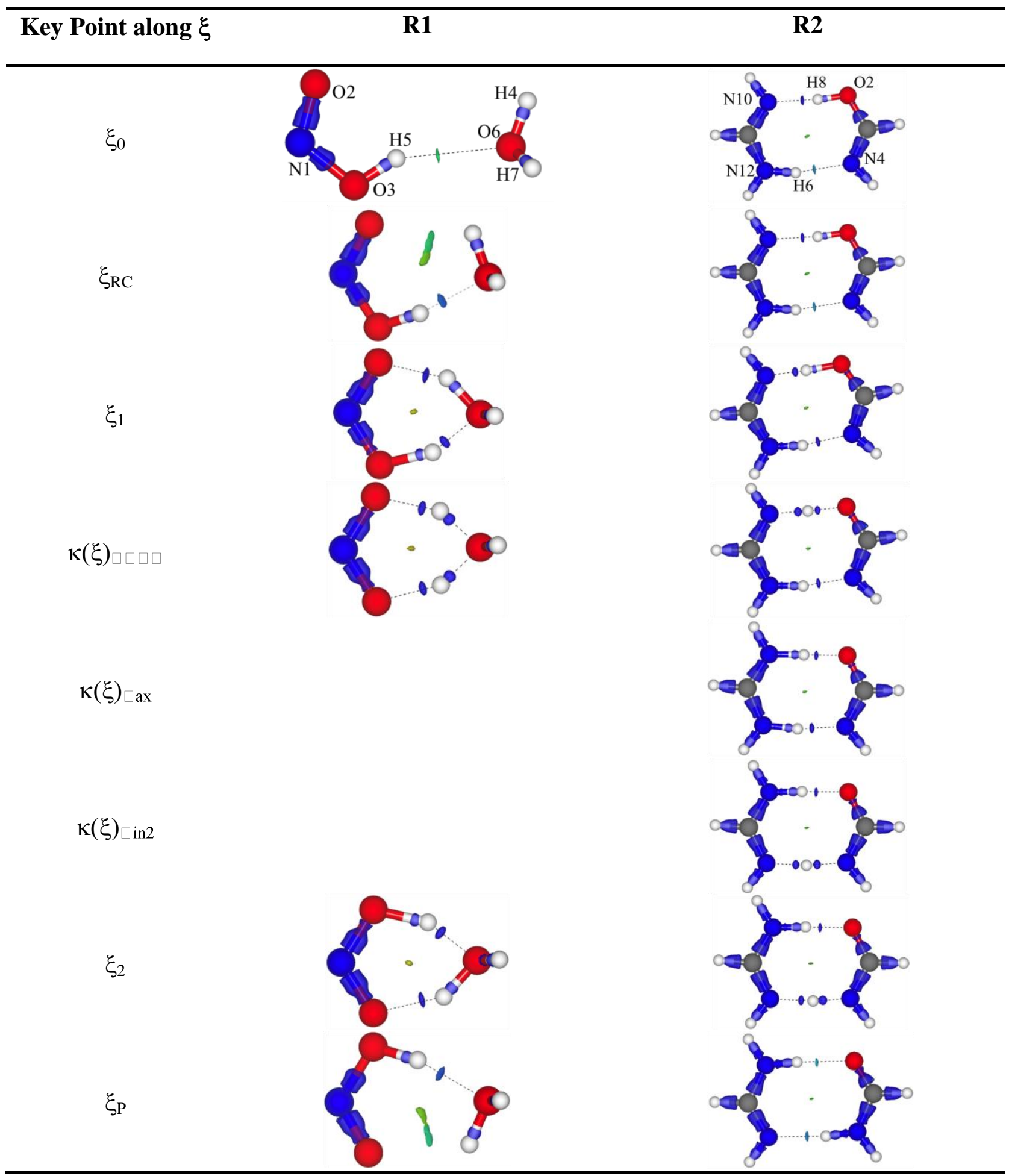


In $\mathbf{R 1}$ the NCI profile of the $\mathrm{N}-\mathrm{O}$ bonds in $\mathrm{HNO}_{2}$ shows large asymmetric $s$ isosurfaces with a flat shape towards the most electropositive atom $(\mathrm{N})$ and a round one in the proximities of the electronegative one $(\mathrm{O}){ }^{45}$ The character of these bonds is interconverted from single into double along the transformation, going all of them through an intermediate bond order at the TS. Along the protons exchange reaction, the main changes are noted in both the covalent $\mathrm{O}-\mathrm{H}$ bonds and the $\mathrm{H} \cdots \mathrm{O}$ intermolecular non-covalent interactions. Namely, at the initial state at $\xi_{0}$, a weak hydrogen bonding is established between H5 and O6 as a localized dispersive interactions (see Table 1). The covalent $\mathrm{O}-\mathrm{H}$ bond involved in the $\mathrm{O} 3-\mathrm{H} 5$ is weaker (red-shift) than the $\mathrm{O} 6-\mathrm{H} 4$ (which is not involved in any H-bonding). This feature is reflected in the electron density at the BCP as displayed Figure 4: $\rho_{\mathrm{BCP}}(\mathrm{O} 3-\mathrm{H} 5)=0.345$ au vs. $\rho_{\mathrm{BCP}}(\mathrm{O} 6-\mathrm{H} 4)=0.371 \mathrm{au}$.
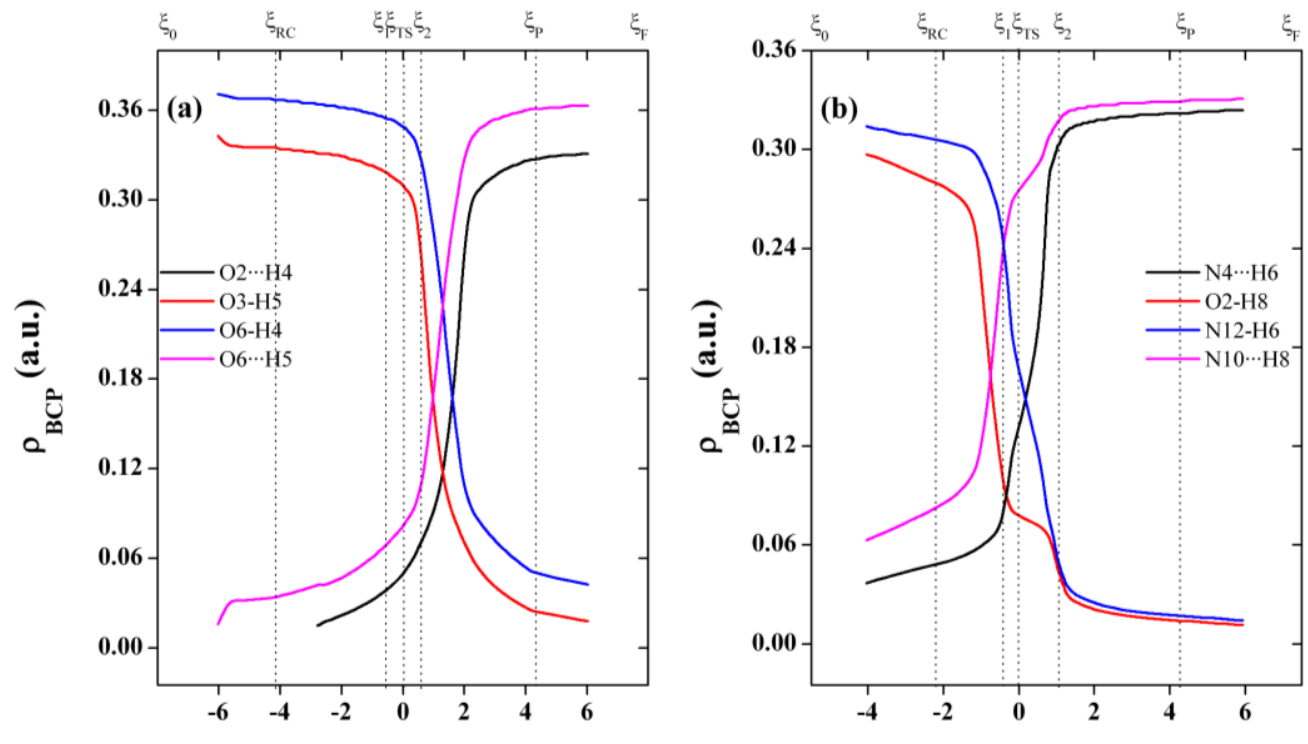

Intrinsic Reaction Coordinate, $\xi$

Intrinsic Reaction Coordinate, $\xi$

Figure 4. Electron density at the BCP (in a.u.) along $\xi$ for $\mathbf{R 1}$ (a) and $\mathbf{R 2}$ (b).

The formation of the H-bonded complex at $\xi_{\mathrm{RC}}$ is guided by new dispersive interactions established between $\mathrm{N}-\mathrm{O} 2$ double bond and $\mathrm{H} 4$. These interactions (depicted in green in Table 1) 
are highly delocalized. It should be noted that this interaction does not lead to a bond critical point until the proximity of the minimum force at $\xi_{1}\left(\rho_{\mathrm{BCP}}(\mathrm{O} 2-\mathrm{H} 4)=0.039\right.$ au at $\left.\xi_{1}\right)$, and, as highlighted before, NCI is a useful tool to identify non-covalent interactions at a much very lower value of density. ${ }^{44,50}$ At $\xi_{\mathrm{RC}}$, the system has two H-bonding interactions, O6-H5 and O2-H4. Nonetheless, they are quite different in nature. Specifically, from Figure 4a we can see that O6H5 falls into a classical hydrogen bond $(\mathrm{HB})\left(\rho_{\mathrm{BCP}}=0.042 \mathrm{au}\right)$ and a well-defined disk-like shape $s$ isosurface (Table 1), indicative of a localized interaction. On the contrary, O2-H4 corresponds to a delocalized interaction, with an extended and diffuse $s$ isosurface, and a lower density at the $\mathrm{BCP}\left(\rho_{\mathrm{BCP}}=0.015 \mathrm{au}\right)$. This evolves progressively into a more localized interaction achieving a classical HBs character within the first part of the transition region. Such changes are not occurring at the expense of the covalent $\mathrm{O}-\mathrm{H}$ bonds (note the flatness of their $\mathrm{BCP}$ densities in Figure 3a).

As it can be seen in Table 1, the TS is characterized by nearly symmetrical NCI profiles around $\mathrm{O} 6, \mathrm{O} 2$ and $\mathrm{O} 3$ atoms, unveiling that the strength of both intramolecular and intermolecular interactions are rather similar $\left(\rho_{\mathrm{BCP}}(\mathrm{O} 6-\mathrm{H} 4)=0.349\right.$ au vs. $\rho_{\mathrm{BCP}}(\mathrm{O} 3-\mathrm{H} 5)=0.310 \mathrm{au}$ and $\rho_{\mathrm{BCP}}(\mathrm{O} 2-\mathrm{H} 4)=0.050$ au vs. $\left.\rho_{\mathrm{BCP}}(\mathrm{O} 6-\mathrm{H} 5)=0.082 \mathrm{au}\right)$. The fact that both chemical events happen at the same time highlights the symmetric nature of the reaction from the electronic viewpoint. The reaction phase ends with the simultaneous transfer of $\mathrm{H} 4$ from $\mathrm{O} 6$ to $\mathrm{O} 2$ $\left(\rho_{\mathrm{BCP}}(\mathrm{O} 6-\mathrm{H} 4)=0.050\right.$ au vs. $\left.\rho_{\mathrm{BCP}}(\mathrm{O} 2-\mathrm{H} 4)=0.327 \mathrm{au}\right)$ and $\mathrm{H} 5$ transfer from $\mathrm{O} 3$ to $\mathrm{O} 6\left(\rho_{\mathrm{BCP}}(\mathrm{O} 3-\right.$ $\mathrm{H} 5)=0.025 \mathrm{au}$ vs. $\left.\rho_{\mathrm{BCP}}(\mathrm{O} 6-\mathrm{H} 5)=0.361 \mathrm{au}\right)$ at $\xi_{\mathrm{P}}$, forming a H-bonded complex.

The NCI analysis also reveals the synchronous character of the reaction (see Table 1). The $s$ profiles for the main reaction points are symmetrically equivalent. Similarly, the TS structure 
has mirror symmetry. This pattern along $\xi$ is originated in the encounter mode between $\mathrm{HNO}_{2}$ and $\mathrm{H}_{2} \mathrm{O}$.

The double proton transfer reactions can be seen as self-neutralization-acid-base reactions. Thus, the synchronous or asynchronous character can be understood on the basis of the difference of the respective pKa of the molecules that form the H-bonded complexes. In this context, the reaction $\mathbf{R} 1$ is given by the H-bonded complexes between $\mathrm{HNO}_{2}$ and $\mathrm{H}_{2} \mathrm{O}$, whose aqueous pKa's are 3.29 and 14 , respectively. ${ }^{61}$ On the contrary, $\mathbf{R 2}$ is controlled by the H-bonded complex between FMA and FI, with corresponding pKa's values of 14 and 28.5 (measured in DMSO). ${ }^{62,63}$

The reaction $\mathbf{R 2}$ (see Scheme 2) proceeds by means of an asymmetric TS. Specifically, within the TS an amidinic and a formamidic proton (H6 and H8) migrates to a nitrogen (N4 and N10), respectively. As a consequence of the difference on the pKa's of these moieties, the two proton migrations occur at different stages of the IRC, leading to a highly asynchronous process. In particular the formamidic proton H8 migrates sooner (before the TS) than the amidinic one H6, whose transference takes place after the TS as displayed the last column of Table 1. Note that the mere inspection of the TS would lead to the wrong conclusions.

From the NCI profiles included in Table 1, we can observe that strong intermolecular interactions are early recognized at $\xi_{0}$, (though they are different in nature than in $\mathbf{R} \mathbf{1}$ since there are two localized dispersive interactions). Once again, intramolecular bonds within the each backbone present a polar character.

At the RC, the strength of intra $(\mathrm{O} 2-\mathrm{H} 8$ and $\mathrm{N} 12-\mathrm{H} 6)$ and intermolecular bonds $(\mathrm{N} 10 \cdots \mathrm{H} 8, \mathrm{~N} 4 \cdots \mathrm{H} 6)$ shows some differences (see Figure $4 \mathrm{~b})$; the density at the BCP of O2-H8 bond is lower than $\mathrm{N} 12-\mathrm{H} 6\left(\rho_{\mathrm{BCP}}(\mathrm{O} 2-\mathrm{H} 8)=0.280\right.$ au vs. $\left.\rho_{\mathrm{BCP}}(\mathrm{N} 12-\mathrm{H} 6)=0.306 \mathrm{au}\right)$ which explain 
the lability of $\mathrm{H} 8 . \rho_{\mathrm{BCP}}(\mathrm{O} 2-\mathrm{H} 8)$ decreases monotonically as the reaction advances until the minimum force is reached at $\xi_{1}$. After, it keeps constant along the transition region. From this decoupled movement of $\mathrm{H} 8$ arises the first minimum of $\kappa(\xi), \kappa(\xi)_{\min 1} \cdot 15$

On the contrary, the strength of the N12-H6 bond monotonically decreases, but until the maximum force at $\xi_{2}$, indicating that it breaks in a more advanced point of the IRC, the motion of H6 originates the second minimum of $\kappa(\xi), \kappa(\xi)_{\min 2 .}{ }^{15}$ At this degree of progress, the reaction the electron density of both bonds are equivalent $\left(\rho_{\mathrm{BCP}}(\mathrm{O} 2-\mathrm{H} 8)=0.042 \mathrm{au}\right.$ vs. $\rho_{\mathrm{BCP}}(\mathrm{N} 12-\mathrm{H} 6)=0.047$ au) and they remain constant afterwards, indicating that the classical HBs are formed .

Alike the previous reaction, in the case of $\mathbf{R} \mathbf{2}$, there are two hydrogen bonds with different strengths at $\xi_{\mathrm{RC}}$ (Figure $\left.4 \mathrm{~b}\right)$ : whereas H6 is strongly bonded to N12 ( $\rho_{\mathrm{BCP}}=0.306$ au) and just forming a weak $\mathrm{HB}$ with $\mathrm{N} 4\left(\rho_{\mathrm{BCP}}=0.048 \mathrm{au}\right), \mathrm{H} 8$ establishes weaker intramolecular bond to $\mathrm{O} 2$ $\left(\rho_{\mathrm{BCP}}=0.280 \mathrm{au}\right)$ and stronger $\mathrm{HB}$ to $\mathrm{N} 10\left(\rho_{\mathrm{BCP}}=0.082 \mathrm{au}\right)$. Thus, H8 is earlier transferred than H6 with a high degree of synchronicity between H-bonding breaking and formation within the $\mathrm{N} 10 \cdots \mathrm{H} 8 \cdots \mathrm{O} 2$ backbone (see the profile at $\xi=\kappa(\xi)_{\min 1}$ in Table 1). This pattern is slightly modified, but emphasizing that the new N10-H8 bond begins to be formed close to $\kappa(\xi)$ min2 (see Table 1). Hence, contrarily to R1, the hydrogen transfers occur before (H8) and after (H6) the TS. Then, we can identify a transition region in the range $\left[\kappa(\xi)_{\min 1}-\kappa(\xi)_{\min 2}\right]$ (see Figure $3 b$ ). The whole transition region in between corresponds to changes of HBs strength without significant hydrogen movements. However, in this case the TS is separated from the highly symmetric structure, which corresponds to $\kappa(\xi)_{\max }$. At $\kappa(\xi)_{\max }$, we can see that both hydrogen atoms are found at a similar electron environments with respect to both fragments (see Table 1). Note that the electron density profiles are different at the reactant side than at the product side. This pattern 
suggests that the closeness in the former region is an indicative that through-bond interactions (delocalization) are predominant while the separation in the latter side is an indicative that through-space interactions (localization) are predominant. While this observation explains the kinetics feasibility in the forward direction of $\mathbf{R} 2$, the behavior of NCI profiles (strength of hydrogen bonding interactions) along the transition region explain the degree of asynchronicity in the mechanism.

Contrary to other studies where the chemical arrangement occurs closely around the TS, in this case, the analysis of second derivatives coincides with the electron density analysis in finding the range of proton transfer (outside the minimum force-maximum force region!) and to identify the $\mathbf{T S}$ as a region of transition, where all interactions are weak.

\section{Diels-Alder Cycloadditions: Synchronous vs. Asynchronous Mechanisms.}

Another multi-bond reaction analyzed in the present study is the Diels-Alder ${ }^{64}$ cycloaddition of an alkene (or dienophile) to a diene. These processes are widely known for being a very useful synthetic tool in organic chemistry to coalesce two pairs of C-C atoms through new single bonds to produce cyclic or bicyclic adducts. The reactions under study consist on the addition of a symmetrically and an asymmetrically di-substituted dienophile to the cyclopentadiene. Specifically, we considered the addition of cis-1,2-dicyanoethylene (R3) and 1,1-dicyanoethylene (R4), as displayed in Scheme 3. Notice that the atoms labels are included for the ulterior density analysis at the $\mathrm{BCP}$ along $\xi$. 


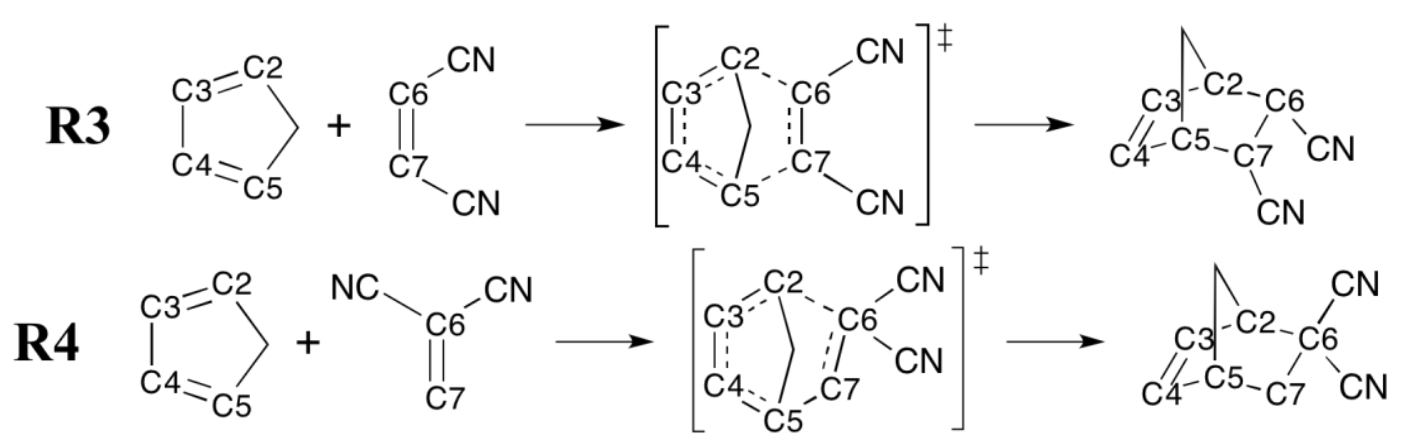

Scheme 3. Diels-Alder reactions between cyclopentadiene and cyanoethylenes.

The addition of the dienophiles to cyclopentadiene is suprafacial, being the endo isomer generally generated. While $\mathbf{R 3}$ proceeds via symmetrical TS, R4 does so via an asymmetrical one. Figure 5a-f shows the profiles of $\mathrm{U}(\boldsymbol{\xi})(\mathrm{a}-\mathrm{b}), \mathbf{F}(\boldsymbol{\xi})(\mathrm{c}-\mathrm{d})$ and $\kappa(\xi)$ (e-f) for $\mathbf{R 3}$ (left-panels) and R4 (right-panels), respectively. As for the previous set of reactions, in addition to the minimum energy path provided by IRC calculations, we included (in the reactant side) the formation of the reactive complexes (i.e. RC) as suggested Figure 1b. Concomitantly, the profile can again be divided into two phases: (I) the initial formation of $\mathbf{R C}$ and (II) the cycloaddition reaction, which leads to the formation of six-membered carbocyclic products.

As in the case of the double proton exchange reactions, in the first phase (I), i.e. from $\xi_{0}$ to $\xi_{\mathrm{RC}}$, the formation of the van der Waals complex between diene and dienophile takes place, in this case through an endo approach and interacting $\mathrm{C} 2 \cdots \mathrm{C} 6 / \mathrm{C} 5 \cdots \mathrm{C} 7$ atoms in both $\mathbf{R 3}$ and $\mathbf{R 4}$ (see Scheme 3). The formation of $\mathbf{R C}$ is also a barrier-free process and is slightly more favored in $\mathbf{R} 4$ than in the corresponding $\mathbf{R} 3$ reaction (7.4 vs. $6.6 \mathrm{kcal} \mathrm{mol}^{-1}$, respectively).

After the formation of $\mathbf{R C}$, the cycloaddition takes place, which is labeled as part (II) in Figure 5 and this region is again partitioned into three zones: II-a, II-b and II-c. This part corresponds to that provided by the IRC calculations and described in Figures 2a-f. 
Therefore, the amount of energy required to overcome the structural distortions in the socalled reactant region (from $\xi_{\mathrm{RC}}$ to $\xi_{1}$ ) is higher in $\mathbf{R 3}$ than the analogous in $\mathbf{R 4}$ (12.5 vs. $9.2 \mathrm{kcal}$ $\left.\mathrm{mol}^{-1}\right)$. The two energy terms $\left(\mathrm{U}\left(\xi_{\mathrm{TS}}\right)-\mathrm{U}\left(\xi_{1}\right)\right)$ and $\left(\mathrm{U}\left(\xi_{2}\right)-\mathrm{U}\left(\xi_{\mathrm{TS}}\right)\right)$ involved along the transition region (part II-b) that are associated with electronic reorganizations are, respectively, 4.8 and $21.2 \mathrm{kcal} \mathrm{mol}^{-1}$ for $\mathbf{R 3}$ and 4.0 and $-24.7 \mathrm{kcal} \mathrm{mol}^{-1}$ for $\mathbf{R 4}$. Consequently, the activation energies and contributions with respect to $\mathbf{R C}$ are: 17.3 (12.5 \& 4.8) $\mathrm{kcal} \mathrm{mol}^{-1}$ for $\mathbf{R 3}$ and 13.2 (9.2 \& 4.0) $\mathrm{kcal} \mathrm{mol}^{-1}$ for $\mathbf{R 4}$. As for the previous set, we noted that the barrier is mainly controlled by structural rearrangements rather than by electronic reorganizations, being $\mathbf{R} 4$ the most kinetically feasible reaction. Also notice that the first part of the relaxation process (i.e. from $\xi_{\mathrm{TS}}$ to $\xi_{2}$ ) is more favored in $\mathbf{R 4}$ than in $\mathbf{R 3}$, by around $3 \mathrm{kcal} \mathrm{mol}^{-1}$. This suggests a difference in the degree of the advance of the new C-C single bonds. This can be seen in Table 2, which reveals that the non-substituted $\mathrm{C}$ atom of the 1,1-dicyanoethylene reacts earliest than the substituted one.

At the final stage, (part II-c, from $\xi_{2}$ to $\xi_{\mathrm{P}}$ ), the amount of energy released in the conformational relaxation to finally lead to the formation of the carbocyclic product is more highly favored for $\mathbf{R 3}$ than for $\mathbf{R} 4$ (-20.9 vs. $-13.1 \mathrm{kcal} \mathrm{mol}^{-1}$ ). This, again, suggests that the formation of new C-C bonds is proceeding in a more decoupled manner in $\mathbf{R 4}$ than in $\mathbf{R 3}$. As already mentioned, the sum of the last four terms provides the thermodynamic driving force. In the case of the cycloadditions, it is found that $\mathbf{R 3}$ presents a slightly higher thermodynamic feasibility than $\mathbf{R 4}$ (-25.5 vs. $-24.6 \mathrm{kcal} \mathrm{mol}^{-1}$ ). It is interesting to note that the exothermicity is quite similar for both reactions, while the activation barriers are well differentiated. Therefore, these reactions cannot be explained in terms of the Bell-Evans-Polanyi principle ${ }^{65,66}$ but by the mechanistic concept of synchronicity or nonsynchronicity as will be discussed in the next paragraphs. 

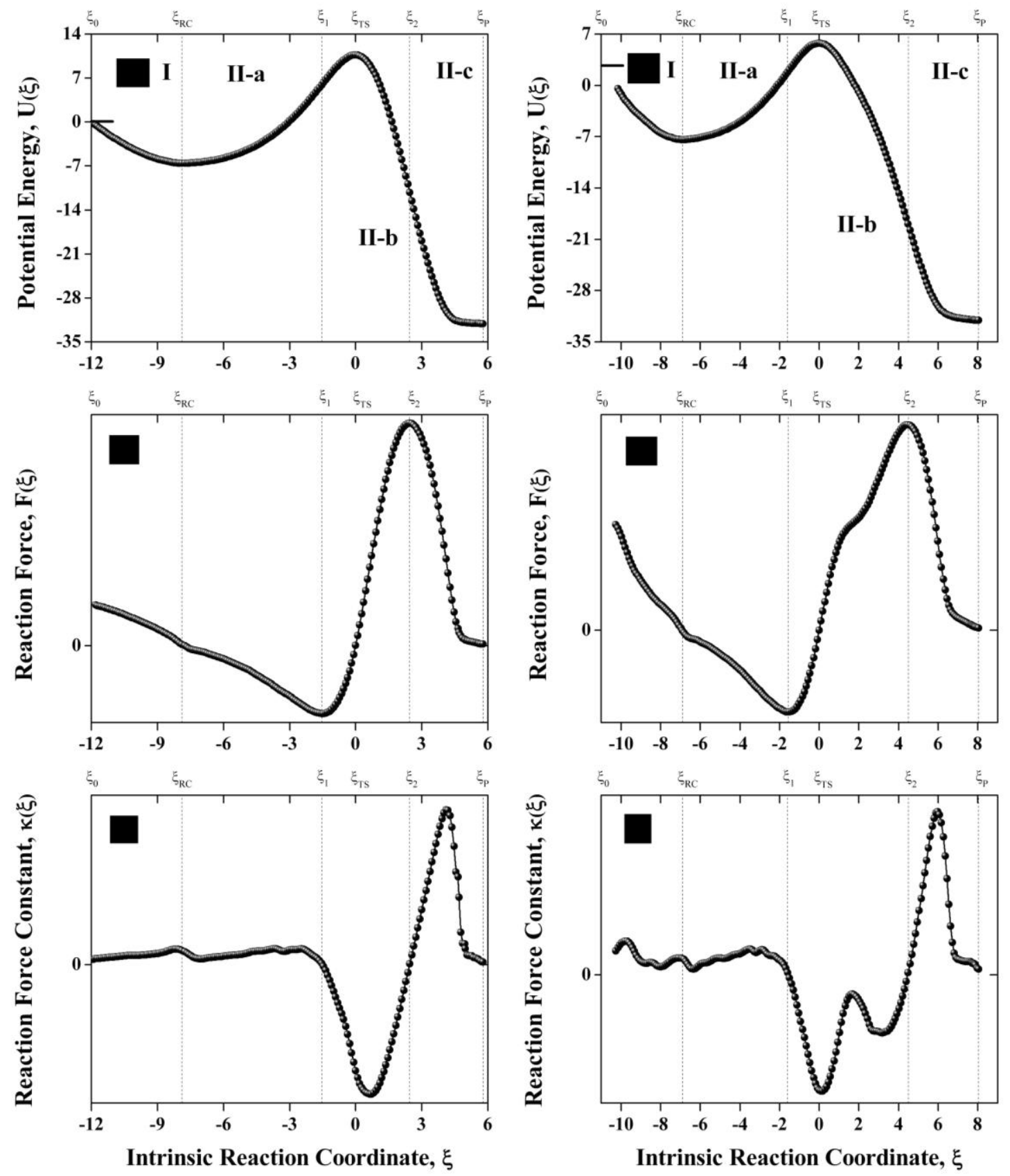

Figure 5. Profiles of $\mathrm{U}(\xi), \mathrm{F}(\xi)$ and $\kappa(\xi)$ along $\xi$ for synchronous R3 (left-panels) and asynchronous R4 (right-panels) Diels-Alder cycloadditions reactions.

The $\mathbf{F}(\xi)$ unveils a certain resemblance along the structurally-intensive zones, i.e. II-a and II-c. On the contrary the differences are evidenced along the transition regions, i.e. II-b zone regions. While $\mathbf{F}(\xi)$ increases linearly along the transition region in $\mathbf{R 3}$, it does so non-linearly in 
R4. Once again, the energy barrier, $\xi_{2}-\xi_{1}$, is broader for $\mathbf{R 4}$ than for $\mathbf{R 3}$ (see Figure 5c-d, respectively). The primitive processes associated with the formation of new C-C single bonds are occurring in a different manner, as confirmed by the $\kappa(\xi)$ profiles that are markedly distinctive in the respective II-b zone. The fine structure shows a single minimum of $\kappa(\xi)$ within along the transition region for $\mathbf{R 3}$ (see Figure 5e) whereas for $\mathbf{R} \mathbf{4}$ it exhibits a local negative maximum connecting the two minima of $\kappa(\xi)$ located on each side (see Figure 5f). On the basis of these patterns the formation of new bonds is fully or slightly orchestrated in $\mathbf{R 3}$, while it is nonorchestrated in R4 (or two-stage one-step mechanism), suggesting that the asynchronous character of $\mathbf{R} \mathbf{4}$ could also explain its kinetical feasibility.

The difference with the double proton transfer reactions discussed above deserves further discussion. For the proton transfer reactions, it was noted that a large difference in the stabilization energies of the $\mathrm{H}$-bonded reactive complexes refereed to the isolated molecules took place. This early recognition was proposed as responsible of both the kinetic feasibility and the mechanistic issues as synchronicity or nonsynchronicity. In spite of the fact that for the case of the Diels-Alder reactions the difference in the stability of the pre-organized complexes refereed to the isolated molecules is rather small, this cannot explain the kinetic feasibility, but whether can give an explanation of the synchronicity patterns in the mechanism, going beyond the (a)symmetry criterion.

The non-covalent interactions were thoroughly studied by means of the NCI index on the key points along $\xi$ defined by $\mathbf{F}(\xi) / \kappa(\xi)$ analysis (see Table 2 ). 
Table 2. Plots of the NCI index along the key points for $\mathbf{R 3}$ and $\mathbf{R 4}$.

Key Point along $\xi$


The Diels-Alder cycloadducts are built as a consequence of the formation of two new C-C single bonds (C2-C6 \& $\mathrm{C} 5-\mathrm{C} 7)$ and a $\mathrm{C}-\mathrm{C}$ double bond (C3-C4), at the expense of breaking two C-C double bonds (C2-C3 \& C4-C5). As it can be seen in Table 2, the NCI profiles for both reactions at the initial stage (from $\xi_{0}$ to $\xi_{\mathrm{RC}}$ ) allow to identify the covalent bonds (single and double character) in both diene and dienophile backbones. This feature is revealed by the electron density analysis, as displayed Figure 6a-b (note that the pink/green and red/black lines are superposed in Figure 6a), which, as expected, shows higher densities in the C-C double bonds $\left(\rho_{\mathrm{BCP}}(\mathrm{C} 2-\mathrm{C} 3)=\rho_{\mathrm{BCP}}(\mathrm{C} 4-\mathrm{C} 5)=\rho_{\mathrm{BCP}}(\mathrm{C} 6-\mathrm{C} 7)=0.336\right.$ au for both $\mathbf{R 3}$ and $\left.\mathbf{R 4}\right)$ than in the $\mathrm{C}-\mathrm{C}$ single bonds $\left(\rho_{\mathrm{BCP}}(\mathrm{C} 3-\mathrm{C} 4)=0.272\right.$ au for both $\mathbf{R 3}$ and $\left.\mathbf{R 4}\right)$ at $\xi_{\mathrm{RC}}$. These moieties are stabilized by weak dispersive van der Waals interactions as they are brought closer to each other, exhibiting the typical diffuse $s$ profile and low electron densities as displayed Figure 6a-b $\left(\rho_{\mathrm{BCP}}(\mathrm{C} 2-\right.$ $\mathrm{C} 6)=\rho_{\mathrm{BCP}}(\mathrm{C} 5-\mathrm{C} 7)=0.009$ au for both $\mathbf{R 3}$ and $\left.\mathbf{R 4}\right)$ at $\xi_{\mathrm{RC}}$. Notice that the $s$ profile is more extended for $\mathbf{R 4}$ than for $\mathbf{R 3}$ and that a localized interaction is observed between the unsubstituted $\mathrm{C}$ atom (C7) of dienophile and $\mathrm{C} 5$ of the diene. This pattern, on the one hand, explains the slightly stabilization of the initial complex of $\mathbf{R 4}$ and, on the other hand, the identified initial recognition between $\mathrm{C} 5$ and $\mathrm{C} 7$ atoms that can promote the asynchronicity in the formation of new C-C bonds unveiled by the $\kappa(\xi)$ analysis. This result deserves to be highlighted since depending on the strength of this type of interaction, it can reveal the origin of the degree of synchronicity vs. nonsynchronicity, beyond a criterion based on the (a)symmetry of the incipient C-C bonds at the $\mathbf{T S} .^{5}$

After the formation of $\mathbf{R C}$ the electron density variations revealed by the NCI profiles are very subtle until the force minimum is reached at $\xi_{1}$. One of them consists of the symmetrically and asymmetrically strengthening of non-covalent interactions, i.e. C2-C6 and C5-C7, for R3 and 
R4, respectively. Interestingly, the small increasing in the electron density at their $\mathrm{BCP}$ is produced at the expense of the intramolecular regions, since double bonds are slightly weakened.
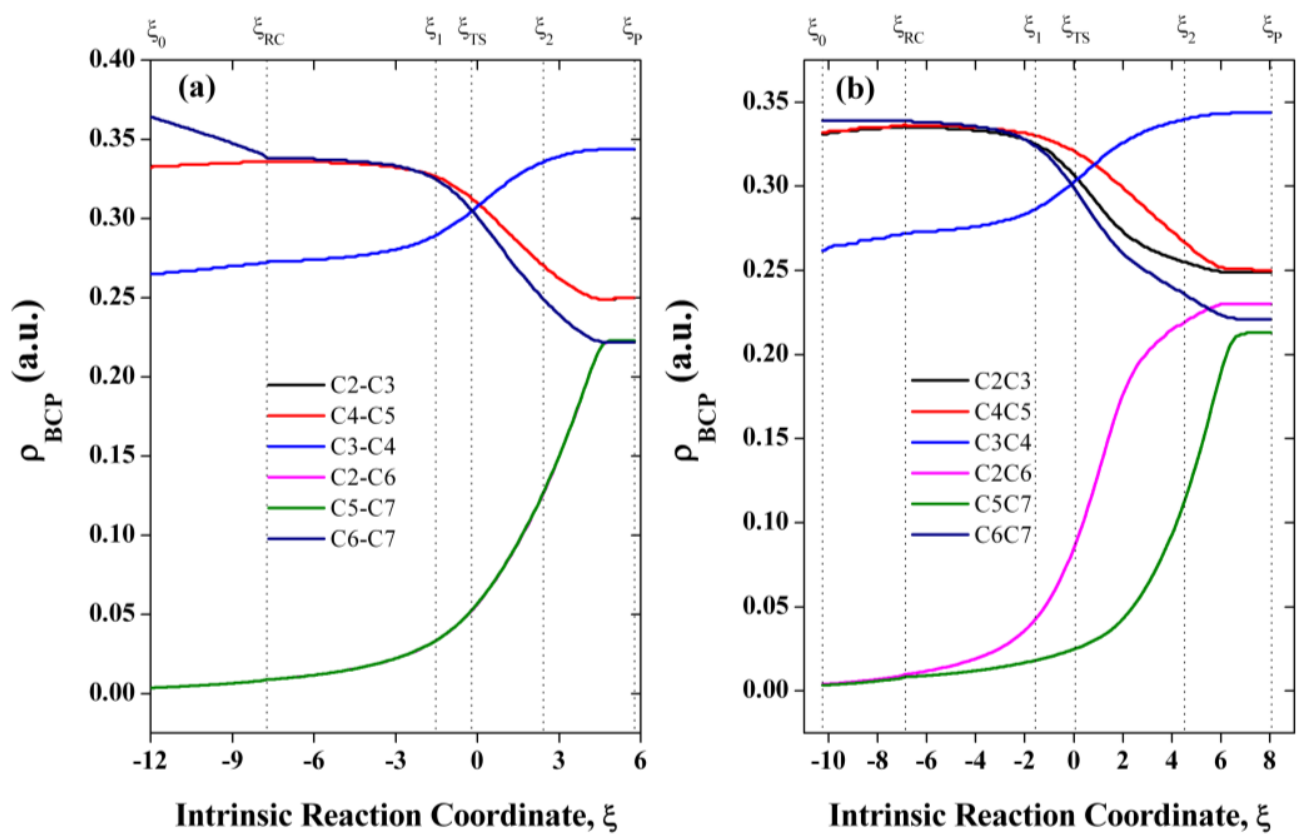

Figure 6. Electron density at the BCP (in a.u.) along $\xi$ for $\mathbf{R 3}$ (a) and $\mathbf{R 4}$ (b).

Along the transition region (from $\xi_{1}$ to $\xi_{2}$ ), weaker bonds start to noticeably become stronger, while double bonds character become progressively weaker. This is indicative of the electronic reorganization being taking place. Here, it should be noted that the tendencies are closer to the unison in $\mathbf{R 3}$ while the changes are decoupled in $\mathbf{R 4}$. Just as in the double proton exchange, the former can be ascribed to the through-space (localization) interactions whereas the latter can be related to the through-bond (delocalization) interactions. At the beginning of the transition zone, from $\xi_{1}$ to $\xi_{\mathrm{TS}}$, both new C-C bonds can be considered to start forming in $\mathbf{R 3}$ whereas only one (between the unsubstituted $\mathrm{C} 7$ of the dienophile and $\mathrm{C} 5$ of the diene) can be considered in R4. This feature is unveiled by the presence of $k(\xi)_{\min 1}$ in both reactions, while the new $\mathrm{C}-\mathrm{C}$ bonds are strengthen along the second part of the transition region, from $\xi_{\mathrm{TS}}$ to $\xi_{2}$, in 
R3. On the contrary, just the first new $\mathrm{C}-\mathrm{C}$ bond makes stronger and the other starts forming in R4 giving rise to the negative maximum of $\kappa(\xi)_{\max }$ and the second new $\mathrm{C}-\mathrm{C}$ bond becomes stronger before leaving the transition region originating the second minima of $\kappa(\xi)$, i.e. $\kappa(\xi)_{\min 2 \text {. }}$ This is in agreement with the energetics analysis above-mentioned.

At the end, the formation of the bonds connecting the diene and the dienophile in $\mathbf{R 3}, \mathbf{C} 2$ C6 and C5-C7, progresses identically (i.e. fully symmetrically) and the resulting bonds are also identical. However, the new double bond, $\mathrm{C} 3-\mathrm{C} 4$, donates some extra electron density to the adjacent single bonds (C2-C3 \& C4-C5), providing them with a slightly higher electron density than that a standard single bond. This constitutes a partial measure of conjugation. The main electronic changes are those related to $\mathrm{C} 3-\mathrm{C} 4$, which undertakes an evolution from simple to double character, finally, acquiring the same electron density as the initial C-C double bonds.

A decrease in the $\mathrm{C} 6-\mathrm{C} 7$ electron density is observed as a $\mathrm{C}-\mathrm{C}$ double bond evolves to a C-C single bond. These observations are the same in $\mathbf{R} \mathbf{4}$, but in a decoupled manner.

As final discussion we want to compare previous BET-based studies applied in DielsAlder reactions with the current approach. These have distinguished several phases (more than three phases), which are characterized by a depletion and formation of the double bonds character and formation of C-C single bonds. ${ }^{27,28}$ However, in those studies the degree of synchronicity/nonsychronicity has not received much attention. Possibly, it could be interesting to combine BET-based with the IRC-based analysis in future investigations. On the other hand, the current approach present some limitation since it is based on an static view, therefore, the inclusion of the dynamic effects could change some conclusion as was recently pointed out by Longo and co-workers. ${ }^{67}$ 


\section{Conclusions}

In the present study our focus of attention has been to find the origin of an important issue in the reaction mechanism, i.e. synchronicity or nonsynchronicity, in prototypical multi-bond chemical reactions, well beyond the criterion based on the symmetry at the TS. We considered two double proton transfer and two cycloaddition reactions that proceed via a symmetrical and asymmetrical TS in each set of reactions. The study was performed by means of combining the reaction force/reaction force constant frame and non-covalent interactions, NCI, index. The $\kappa(\xi)$ profile along the transition region has been already proposed as a suitable indicator of the degree of (a)synchronicity in multi-bond reactions depending on its fine structure along the transition region: one minimum of $\kappa(\xi)$ unveils a fully or slightly synchronous process while two minima of $\kappa(\xi)$ connected by a negative maximum of $\kappa(\xi)$ does for asynchronous or two-stage one-step mechanism. Special attention has been paid on unraveling the role played by the early molecular recognition in determining the degree of (a)synchronicity in one-step mechanism. Our results showed that the early intermolecular interaction in the pre-organized complexes can predetermine and solve this mechanistic issue, where a differential early intermolecular recognition between the reactive atomic centers were stressed along the activation process, so determining a highly asynchronous character in the mechanism, the so-called two-stage one step mechanism. Consequently, the real space approach to the reaction force is a useful tool to characterize the kinetic, thermodynamic driving force and mechanistic aspects of multi-bond chemical reactions.

\section{Acknowledgment.}

This paper is dedicated to professor Paul Geerlings Festschrift on occasion of his $70^{\text {th }}$ birthday and to celebrate his important contributions in the Conceptual Density Functional Theory field. We also acknowledge to FONDECYT grant with the project number 1181914 for the financial support. J.M. gratefully acknowledges the financial support from the Spanish Ministerio de Ciencia, Innovación y Universidades (FPU14/06003 and EST17/00161) and from the Universidad de Zaragoza, the Fundación Bancaria Ibercaja, and Fundación CAI (CB 6/17). 


\section{References}

1. Dewar, M. J. S. Journal of the American Chemical Society 1984, 106(1), 209-219.

2. $\quad$ Black, K.; Liu, P.; Xu, L.; Doubleday, C.; Houk, K. N. Proceedings of the National Academy of Sciences 2012, 109(32), 12860-12865.

3. Xu, L.; Doubleday, C. E.; Houk, K. N. Journal of the American Chemical Society 2010, 132(9), 3029-3037.

4. Yepes, D.; Murray, J. S.; Pérez, P.; Domingo, L. R.; Politzer, P.; Jaque, P. Physical Chemistry Chemical Physics 2014, 16(14), 6726-6734.

5. Yepes, D.; Valenzuela, J.; Martínez-Araya, J. I.; Pérez, P.; Jaque, P. Physical Chemistry Chemical Physics 2019, 21(14), 7412-7428.

6. Yepes, D.; Donoso-Tauda, O.; Pérez, P.; Murray, J. S.; Politzer, P.; Jaque, P. Physical Chemistry Chemical Physics 2013, 15(19), 7311-7320.

7. $\quad$ Politzer, P.; Murray, J. S.; Jaque, P. Journal of Molecular Modeling 2013, 19(10), 4111-4118.

8. Caramella, P.; Houk, K. N.; Domelsmith, L. N. Journal of the American Chemical Society 1977 , 99(13), 4511-4514.

9. Domingo, L. R.; Aurell, M. J.; Perez, P.; Contreras, R. Journal of Organic Chemistry 2003, 68(10), 3884-3890.

10. Linder, M.; Brinck, T. Physical Chemistry Chemical Physics 2013, 15(14), 5108-5114.

11. Jaque, P.; Toro-Labbé, A.; Politzer, P.; Geerlings, P. Chemical Physics Letters 2008, 456(4-6), 135-140.

12. Toro-Labbé, A. Journal of Physical Chemistry A 1999, 103(22), 4398-4403.

13. Paredes-Gil, K.; Mendizábal, F.; Jaque, P. Journal of Molecular Modeling 2019, 25(10), 305.

14. Yepes, D.; Murray, J. S.; Santos, J. C.; Toro-Labbe, A.; Politzer, P.; Jaque, P. Journal of Molecular Modeling 2013, 19(7), 2689-2697.

15. Yepes, D.; Murray, J. S.; Politzer, P.; Jaque, P. Physical Chemistry Chemical Physics 2012, 14(31), 11125-11134.

16. Politzer, P.; Murray, J. S.; Yepes, D.; Jaque, P. Journal of Molecular Modeling 2014, 20(8), 2351.

17. Murray, J. S.; Yepes, D.; Jaque, P.; Politzer, P. Computational and Theoretical Chemistry 2015, $1053,270-280$.

18. Yepes, D.; Martínez-Araya, J. I.; Jaque, P. Journal of Molecular Modeling 2017, 24(1), 33.

19. Fukui, K. Accounts of Chemical Research 1981, 14(12), 363-368.

20. Gonzalez, C.; Schlegel, H. B. Journal of Physical Chemistry 1990, 94(14), 5523-5527.

21. Suárez, D.; A. Sordo, J. Chemical Communications 1998(3), 385-386.

22. Domingo, L. R.; Perez, P.; Saez, J. A. Organic \& Biomolecular Chemistry 2012, 10(19), 38413851 .

23. Domingo, L. R.; Ríos-Gutiérrez, M.; Pérez, P. The Journal of Organic Chemistry 2018, 83(4), 2182-2197.

24. Andrés, J.; González-Navarrete, P.; Safont, V. S.; Silvi, B. Physical Chemistry Chemical Physics 2017, 19(43), 29031-29046.

25. Yepes, D.; Pérez, P.; Jaque, P.; Fernández, I. Organic Chemistry Frontiers 2017, 4(7), 1390-1399.

26. Poree, C.; Schoenebeck, F. Accounts of Chemical Research 2017, 50(3), 605-608.

27. Berski, S.; Andrés, J.; Silvi, B.; Domingo, L. R. The Journal of Physical Chemistry A 2003, 107(31), 6014-6024.

28. Berski, S.; Andrés, J.; Silvi, B.; Domingo, L. R. The Journal of Physical Chemistry A 2006, 110(51), 13939-13947.

29. Polo, V.; Andres, J.; Berski, S.; Domingo, L. R.; Silvi, B. The Journal of Physical Chemistry A 2008, 112(31), 7128-7136.

30. Andres, J.; Berski, S.; Domingo, L. R.; Polo, V.; Silvi, B. Current Organic Chemistry 2011, 15(20), 3566-3575. 
31. Andrés, J.; Gracia, L.; González-Navarrete, P.; Safont, V. S. Computational and Theoretical Chemistry 2015, 1053, 17-30.

32. Yepes, D.; Murray, J.; Santos, J.; Toro-Labbé, A.; Politzer, P.; Jaque, P. Journal of Molecular Modeling 2013, 19(7), 2689-2697.

33. Yepes, D.; Murray, J. S.; Perez, P.; Domingo, L. R.; Politzer, P.; Jaque, P. Phys Chem Chem Phys 2014, 16(14), 6726-6734.

34. Jaque, P.; Toro-Labbé, A. Journal of Physical Chemistry A 2000, 104(5), 995-1003.

35. Politzer, P.; Toro-Labbé, A.; Gutiérrez-Oliva, S.; Herrera, B.; Jaque, P.; Concha, M. C.; Murray, J. S. Journal of Chemical Sciences 2005, 117(5), 467-472.

36. Politzer, P.; Toro-Labbé, A.; Gutiérrez-Oliva, S.; Murray, J. S. In Advances in Quantum Chemistry, Vol 64; Sabin, J. R.; Brandas, E. J., Eds., 2012, p 189-209.

37. Jaque, P.; Toro-Labbé, A.; Geerlings, P.; De Proft, F. Journal of Physical Chemistry A 2009, 113(1), 332-344.

38. Politzer, P.; Burda, J. V.; Concha, M. C.; Lane, P.; Murray, J. S. Journal of Physical Chemistry A 2006, 110(2), 756-761.

39. Politzer, P.; Murray, J. S. Collection of Czechoslovak Chemical Communications 2008, 73(6-7), 822-830.

40. Rincón, E.; Jaque, P.; Toro-Labbé, A. Journal of Physical Chemistry A 2006, 110(30), 9478-9485.

41. Toro-Labbe, A.; Gutierrerez-Oliva, S.; Murray, J. S.; Politzer, P. Molecular Physics 2007, 105(1922), 2619-2625.

42. Polanyi, J. C.; Zewail, A. H. Accounts of Chemical Research 1995, 28(3), 119-132.

43. Zewail, A. H. Journal of Physical Chemistry A 2000, 104(24), 5660-5694.

44. Johnson, E. R.; Keinan, S.; Mori-Sánchez, P.; Contreras-García, J.; Cohen, A. J.; Yang, W. Journal of the American Chemical Society 2010, 132(18), 6498-6506.

45. Lane, J. R.; Contreras-García, J.; Piquemal, J.-P.; Miller, B. J.; Kjaergaard, H. G. Journal of Chemical Theory and Computation 2013, 9(8), 3263-3266.

46. Bader, R. F. W. Chemical Reviews 1991, 91(5), 893-928.

47. González, L.; Tejedor, R. M.; Royo, E.; Gaspar, B.; Munárriz, J.; Chanthapally, A.; Serrano, J. L.; Vittal, J. J.; Uriel, S. Crystal Growth \& Design 2017, 17(12), 6212-6223.

48. Munárriz, J.; Rabuffetti, F. A.; Contreras-García, J. Crystal Growth \& Design 2018, 18(11), 69016910.

49. Lee, J.-H.; Bristowe, N. C.; Bristowe, P. D.; Cheetham, A. K. Chemical Communications 2015, 51(29), 6434-6437.

50. Contreras-García, J.; Calatayud, M.; Piquemal, J.-P.; Recio, J. M. Computational and Theoretical Chemistry 2012, 998, 193-201.

51. Boto, R. A.; Contreras-García, J.; Tierny, J.; Piquemal, J.-P. Molecular Physics 2016, 114(7-8), 1406-1414.

52. Becke, A. D. Journal of Chemical Physics 1993, 98(7), 5648-5652.

53. Stephens, P. J.; Devlin, F. J.; Chabalowski, C. F.; Frisch, M. J. Journal of Physical Chemistry 1994, 98(45), 11623-11627.

54. Chai, J.-D.; Head-Gordon, M. Physical Chemistry Chemical Physics 2008, 10(44), 6615-6620.

55. González-Rivas, N.; Cedillo, A. Journal of Chemical Sciences 2005, 117(5), 555-560.

56. Frisch, M. J. T., G. W.; Schlegel, H. B.; Scuseria, G. E.; Robb, M. A.; Cheeseman, J. R.; Scalmani, G.; Barone, V.; Mennucci, B.; Petersson, G. A.; Nakatsuji, H.; Caricato, M.; Li, X.; Hratchian, H. P.; Izmaylov, A. F.; Bloino, J.; Zheng, G.; Sonnenberg, J. L.; Hada, M.; Ehara, M.; Toyota, K.; Fukuda, R.; Hasegawa, J.; Ishida, M.; Nakajima, T.; Honda, Y.; Kitao, O.; Nakai, H.; Vreven, T.; Montgomery, Jr., J. A.; Peralta, J. E.; Ogliaro, F.; Bearpark, M.; Heyd, J. J.; Brothers, E.; Kudin, K. N.; Staroverov, V. N.; Kobayashi, R.; Normand, J.; Raghavachari, K.; Rendell, A.; Burant, J. C.; Iyengar, S. S.; Tomasi, J.; Cossi, M.; Rega, N.; Millam, J. M.; Klene, M.; Knox, J. E.; Cross, J. B.; Bakken, V.; Adamo, C.; Jaramillo, J.; Gomperts, R.; Stratmann, R. E.; Yazyev, O.; Austin, A. J.; Cammi, R.; Pomelli, C.; Ochterski, J. W.; Martin, R. L.; Morokuma, K.; Zakrzewski, V. G.; Voth, G. A.; Salvador, P.; 
Dannenberg, J. J.; Dapprich, S.; Daniels, A. D.; Farkas, Ã.; Foresman, J. B.; Ortiz, J. V.; Cioslowski, J.; Fox, D. J. Gaussian09: Wallingford CT, 2009.

57. Contreras-García, J.; Johnson, E. R.; Keinan, S.; Chaudret, R.; Piquemal, J.-P.; Beratan, D. N.; Yang, W. Journal of Chemical Theory and Computation 2011, 7(3), 625-632.

58. Andrés, J.; Berski, S.; Contreras-García, J.; González-Navarrete, P. The Journal of Physical Chemistry A 2014, 118(9), 1663-1672.

59.

60. Labet, V.; Morell, C.; Toro-Labbe, A.; Grand, A. Physical Chemistry Chemical Physics 2010, 12(16), 4142-4151.

61. Kolthoff, I. M.; Elving, P. J. Treatise on analytical chemistry; Interscience Encyclopedia: New York, 1959.

62. Bordwell, F. G.; Ji, G. Z. Journal of the American Chemical Society 1991, 113(22), 8398-8401.

63. Bordwell, F. G.; Bartmess, J. E.; Hautala, J. A. The Journal of Organic Chemistry 1978, 43(16), 3095-3101.

64. Diels, O.; Alder, K. Justus Liebigs Annalen Der Chemie 1928, 460, 98-122.

65. Bell, R. P.; Hinshelwood, C. N. Proceedings of the Royal Society of London Series A Mathematical and Physical Sciences 1936, 154(882), 414-429.

66. Evans, M. G.; Polanyi, M. Transactions of the Faraday Society 1938, 34(0), 11-24.

67. de Souza, M. A. F.; Ventura, E.; do Monte, S. A.; Riveros, J. M.; Longo, R. L. Journal of Computational Chemistry 2016, 37(8), 701-711. 